Int. J. Electrochem. Sci., 11 (2016) 5490 - 5506

\title{
Biocorrosion Control of Electroless Ni-Zn-P Coating Based on Carbon Steel by the Pseudomonas aeruginosa Biofilm
}

\author{
Sahar A. Fadl-allah ${ }^{1,3, *}$, A.A. Montaser ${ }^{1,4}$, Sanaa M.F. Gad El-Rab ${ }^{2,5}$ \\ ${ }^{1}$ Materials and Corrosion Lab (MCL), Faculty of Science, Taif University, Taif, KSA \\ ${ }^{2}$ Biotechnology Department, Faculty of Science, Taif University, Taif, KSA \\ ${ }^{3}$ Chemistry Department, Faculty of Science, Cairo University, Cairo, Egypt \\ ${ }^{4}$ Chemistry Department, Faculty of Science, Aswan University, Aswan, Egypt \\ ${ }^{5}$ Botany and Microbiology Department, Faculty of Science, Assuit University,71516 Assuit, Egypt \\ *E-mail: sahar.fadlallah@yahoo.com
}

doi: $10.20964 / 2016.07 .96$

Received: 2 April 2016 / Accepted: 1 May 2016 / Published: 4 June 2016

Pseudomonas aeruginosa ( $P$. aeruginosa) is considered one of the most important microorganisms that show a strong trend to growth on the metal surface and promote the biofilm formation. The present study describes the effect of $P$. aeruginosa (ATCC9027) on the corrosion resistance of electroless nickel-zinc-phosphorous (Ni-Zn-P) alloy coating based on carbon steel C1018. The influence of aerobic bacteria $P$. aeruginosa on the corrosion behavior of C1018 and Ni-Zn-P alloy in artificial sea water was studied by dielectric spectroscopy. Scanning electron microscope, SEM, and energy dispersive X-ray surface analysis techniques were used to distinguish the morphology and chemical composition of the alloy coating surface before and after 28 days of immersion in a nutrient medium. Although, the presence of $P$. aeruginosa in sterile media reduce the value of the corrosion resistance of $\mathrm{C} 1018$ to $691 \Omega$, but it rises the corrosion resistance of Ni-Zn-P alloy up to $28 \mathrm{~K} \Omega$. Quantitative description of the power of the morphology of alloy coating on bacterial affection and biofilm construction was investigated by the plate-counting method. The free biofilm fraction electrode surface (1-Ө) was calculated for $\mathrm{C} 1018$ and $\mathrm{Ni}-\mathrm{Zn}-\mathrm{P}$ to be equal 4.016 and 0.3616 , respectively. These results revealed that the antibacterial performance of the zinc alloy coating is better than the uncoated C1018 and it encourages the formation of passive biofilm protect carbon steel from biocorrosion.

Keywords: Carbon steel, Pseudomonas aeruginosa, Biocorrosion, Biofilm, Ni-Zn-P alloy, EIS, SEM/EDX.

$\underline{\text { FULL TEXT }}$ 
(C) 2016 The Authors. Published by ESG (www.electrochemsci.org). This article is an open access article distributed under the terms and conditions of the Creative Commons Attribution license (http://creativecommons.org/licenses/by/4.0/). 